\title{
SIRT1 and gynecological malignancies (Review)
}

\author{
JIAYU CHEN ${ }^{1}$, HOUZAO CHEN ${ }^{2}$ and LINGYA PAN ${ }^{1}$ \\ ${ }^{1}$ Department of Obstetrics and Gynecology, Peking Union Medical College Hospital, Chinese Academy of Medical Sciences \\ and Peking Union Medical College; ${ }^{2}$ State Key Laboratory of Medical Molecular Biology, Department of Biochemistry \\ and Molecular Biology, Institute of Basic Medical Sciences, Chinese Academy of Medical Sciences \\ and Peking Union Medical College, Beijing 100730, P.R. China
}

Received October 10, 2020; Accepted January 25, 2021

DOI: $10.3892 /$ or.2021.7994

\begin{abstract}
Sirtuin 1 (SIRT1), a member of the sirtuin protein family, is a nicotinamide adenine dinucleotide $\left(\mathrm{NAD}^{+}\right)$-dependent type III histone deacetylase and mono-ADP-ribosyltransferase. SIRT1 can deacetylate histones ( $\mathrm{H} 1, \mathrm{H} 3$, and $\mathrm{H} 4)$ and non-histone proteins, and it is widely involved in various physiological and pathological processes in the body, including metabolism, aging, transcription, DNA damage and repair, apoptosis, cell cycle regulation, inflammation and cancer. Research has shown that SIRT1 is involved in tumorigenesis, tumor metastasis and chemotherapy resistance, but it exerts opposing effects and plays different roles in different pathogenic processes. Recent studies have demonstrated that SIRT1 may be implicated in the pathogenesis, development, treatment and prognosis of tumors; however, its role in gynecological tumors remains elusive. The aim of the present review was to summarize the pathogenic roles of SIRT1 in cancer, and to provide what is, to the best of our knowledge, the first review of recent advances involving SIRT1 in cervical cancer, endometrial cancer (EC) and ovarian cancer (OC). In addition, the critical research gaps regarding SIRT1, particularly its potential involvement in the concurrence of EC and cervical cancer and its antagonistic effect against poly(ADP-ribose) polymerase inhibitors in OC, were highlighted.
\end{abstract}

Correspondence to: Dr Lingya Pan, Department of Obstetrics and Gynecology, Peking Union Medical College Hospital, Chinese Academy of Medical Sciences and Peking Union Medical College, 1 Shuaifuyuan, Dongcheng, Beijing 100730, P.R. China

E-mail: panly@pumch.cn

Professor Houzao Chen, State Key Laboratory of Medical Molecular Biology, Department of Biochemistry and Molecular Biology, Institute of Basic Medical Sciences, Chinese Academy of Medical Sciences and Peking Union Medical College, No. 5, Dongdan San Tiao, Dongcheng, Beijing 100730, P.R. China

E-mail: chenhouzao@ibms.cams.cn; houzao@gmail.com

Key words: sirtuin 1, cervical cancer, endometrial cancer, ovarian cancer, poly(ADP-ribose) polymerase inhibitors

\section{Contents}

1. Introduction

2. Pathogenic function of SIRT1 in malignancies

3. Role of SIRT1 in non-gynecological malignancies

4. Role of SIRT1 in gynecological malignancies

5. Conclusions

\section{Introduction}

Endometrial cancer (EC), cervical cancer and ovarian cancer(OC) are the three most common gynecological malignancies. EC is the most common gynecological tumor in developed countries, and its incidence and mortality are increasing (1). By contrast, the incidence of cervical cancer is decreasing (1) due to the extensive application of the human papillomavirus (HPV) vaccine and the standard screening strategy. However, the incidence and mortality of cervical cancer in developing countries are very different from those in developed countries $(2,3)$. A study conducted in China revealed that cervical cancer had the highest incidence and mortality among gynecological tumors in 2015 (4). OC is the most lethal cancer (1), possibly due to the lack of efficient early diagnostic methods, its high recurrence rate, and its extensive chemoresistance.

Persistent HPV infection is the main cause of cervical cancer (5), but the causes of the other two gynecological cancers have not yet been clearly determined, despite years of research. Multiple factors are involved in EC and OC, among which family history, advanced age, low fertility and low levels of female hormones are considered as high-risk factors $(6,7)$. Standard therapy includes surgery and adjuvant therapy, such as chemotherapy and radiotherapy; furthermore, an increasing number of active agents, such as bevacizumab and poly(ADP-ribose) polymerase (PARP) inhibitors (PARPi), have emerged in recent decades (5-7). However, identifying characteristic markers is the key to improving the diagnosis, treatment and prognosis of these tumors.

Sirtuin 1 (SIRT1), a member of the sirtuin protein family, belongs to the family of type III histone deacetylases and is mainly localized to the nucleus $(8,9)$. SIRT1 can deacetylate histone (H1, H3 and H4) and non-histone proteins [p53 and nuclear factor $(\mathrm{NF})-\kappa \mathrm{B}]$ by consuming nicotinamide adenine dinucleotide $\left(\mathrm{NAD}^{+}\right)$, causing ADP-ribose to attach to the 
acetyl moiety of the substrate, and releasing nicotinamide (NAM) and 2'-O-acetyl-adenosine diphosphate-ribose (O-AcADPR) (10,11). SIRT1 regulates metabolism, aging, transcription, DNA damage and repair, apoptosis, the cell cycle, inflammation, and tumor-related processes, and it is the most extensively investigated sirtuin in mammals $(10,12)$. SIRT1 has been studied in the context of breast cancer, colorectal cancer, liver cancer, melanoma and several other cancers (13), but few studies have reported the involvement of SIRT1 in gynecological malignancies. The aim of the present review was to summarize the pathogenic roles of SIRT1 in gynecological malignancies and reveal the etiological association and therapeutic potential of SIRT1 in EC, cervical cancer and OC.

\section{Pathogenic function of SIRT1 in malignancies}

Genetic damage and repair. Recent research has shown that SIRT1 exerts protective effects on normal cells by preventing DNA damage and promoting DNA repair; however, SIRT1 may exert the same effects on cancer cells, thereby promoting their survival, proliferation and metastasis (13). In addition, SIRT1 exerts carcinogenic effects by deacetylating specific molecules.

After deacetylating histones, SIRT1 affects the chromatin topology and densely binds chromatin into heterochromatin, thereby protecting DNA from the effects of ultraviolet rays and oxidation and further inhibiting the onset of malignancies $(14,15)$. When damage occurs, SIRT1 binds to damaged DNA fragments and changes their transcriptional activity by histone deacetylase and adjacent promoter methylation mediated by the recruitment of DNA methyltransferases (DNMTs) (16-18). Histone methylation is coactivated by complexes consisting of E2H2, DNMTs and $\gamma \mathrm{H} 2 \mathrm{AX}$, and is involved in transcriptional silencing and protection. Additionally, a previous review concluded that SIRT1 facilitates DNA damage repair (DDR), including homologous recombination (HR) repair, non-homologous end-joining (NHEJ) repair, mismatch repair and base excision repair, and regulates the cell cycle through key molecules such as ataxia-telangiectasia mutated (ATM), p53-binding protein 1, KU70, the FOXO family, MSH2, MSH6 and apurinic/apyrimidinic endonuclease APEX1 (Fig. 1) $(13,19)$.

The dissociation of SIRT1 from a previous binding site and its subsequent specific binding to a damaged site to assist in DDR may cause problems. One problem is that separation may alter the chromatin conformation from heterochromatin to euchromatin, lifting the transcriptional suppression of genes that should be transcriptionally silent, which is likely to cause cancer (18). Furthermore, the binding of SIRT1 to damaged fragments should be transient, persisting just long enough to permit repair; otherwise, genes that are supposed to be silent may be expressed and serve as driving factors of tumors.

The deacetylation of targeted proteins may also be involved in carcinogenesis. p53 is a critical tumor suppressor, and deficiency in its expression exists in a variety of malignancies, whereas its activity is significantly reduced when p53 is deacylated (20). The functions of the FOXO family members, which regulate the cell cycle, may be inhibited by SIRT1, thereby enabling damage repair but arresting apoptosis (21).
As a result, many tumor cells with defects in transcription have sufficient time to correct these errors, survive and proliferate.

Metabolism. Tumor cells grow more rapidly compared with normal cells and, thus, they require more energy and materials for proliferation. We found reports of several metabolic changes in the literature, among which glycolipid metabolism is the most fundamental metabolic change (22-24). The majority of tumor cells abide by the particular glucose metabolism principle known as the 'Warburg effect', which refers to the reliance of tumor cells on aerobic glycolysis instead of the tricarboxylic acid cycle to obtain energy $(25,26)$. A likely explanation for this effect is that the process of glycolysis will assemble the necessary materials for cancer cell proliferation, since not all glucose is converted into $\mathrm{CO}_{2}$. Furthermore, the accumulation of lactic acid (the product of glycolysis) promotes cell proliferation and stimulates neovascularization (27). Lipid metabolism also contributes to the proliferation and development of cancer cells. Lipid synthesis provides indispensable materials for cell proliferation, whereas lipolysis offers energy apart from that of glycolysis; both processes involve some essential transcriptional factors, such as peroxisome proliferator-activated receptor (PPAR) $\gamma$ and sterol regulatory element-binding proteins (SREBPs) $(22,24,28)$. SIRT1 has broad and opposite functions in the glucose and lipid metabolism of malignant cells (29-31), as shown in Tables I-III. SIRT1 directly regulates the expression, activity and localization of enzymes involved in glycolysis, and it can also indirectly adjust glucose metabolism by affecting glycolysis-related transcriptional factors (Table I) $(32,33)$. Similarly, the diverse effects of SIRT1 may also be observed in lipid synthesis and lipolysis (Tables II and III) $(32,33)$.

\section{Role of SIRT1 in non-gynecological malignancies}

SIRT1 is associated with tumorigenesis, but its role varies among different organs and tissues; SIRT1 is upregulated in patients with primary colon cancer, prostatic carcinoma, acute myelogenous leukemia, cutaneous melanoma and non-melanoma skin cancer, but it is downregulated in breast cancer and hepatocellular carcinoma (13). However, Moore et al (34) revealed that SIRT1 is overexpressed in estrogen receptor (ER)-positive breast carcinoma, suggesting suppressive and promoting actions in disparate molecular types of malignancies. Moreover, Zhong et al (35) demonstrated that SIRT1 has a negative impact on colorectal cancer by downregulating the expression of key proteins that participate in double-strand break repair, such as BRCA2, RAD50 and FANCA, by impacting the recruitment of hMOF, which belongs to the histone acetyltransferase family. In chronic myeloid leukemia, SIRT1 has been shown to induce BCR-ABL mutations and drug resistance to tyrosine kinase inhibitors $(36,37)$, although Jeong et al (38) reported that SIRT1 enhances the NHEJ pathway by deacetylating and activating KU70.

SIRT1 may also promote tumor invasion and metastasis $(39,40)$. Studies on breast cancer have revealed that SIRT1 can increase epithelial-to-mesenchymal transition (EMT) by overexpressing related transcriptional factors, such as SNAIL 
Table I. Effects of SIRT1 on glycolysis in various tissues.

\begin{tabular}{|c|c|c|}
\hline Regulation & Promoting & Inhibiting \\
\hline Direct & $\begin{array}{l}\text { In pancreatic cancer, SIRT1 upregulates glucose transporters } \\
\text { and other critical enzymes; combination with GAPDH } \\
\text { keeps it in the cytoplasm and prevents it from entering } \\
\text { the nucleus. }\end{array}$ & $\begin{array}{l}\text { In the liver, SIRT1, Forkhead box O3 and } \\
\text { nuclear respiratory factor } 1 \text { form complexes, } \\
\text { increasing the expression of SIRT6, which } \\
\text { would silence glycolysis-associated genes. }\end{array}$ \\
\hline Indirect & $\begin{array}{l}\text { Increases HIF-1 } \alpha, \mathrm{c}-\mathrm{Myc} \text { and liver kinase } \\
\mathrm{B} 1-\mathrm{AMP} \text {-activated protein kinase-dependent glycolysis }\end{array}$ & $\begin{array}{l}\text { SIRT1 can deacetylate and inhibit the activity } \\
\text { of P300, and further decrease the transcription } \\
\text { of HIF- } 1 \alpha \text {; inhibition of glycolysis by activating } \\
\text { peroxisome proliferator-activated receptor } \gamma \\
\text { coactivator } 1 \alpha \text { and phosphoglycerate mutase } 1\end{array}$ \\
\hline
\end{tabular}

SIRT, sirtuin; HIF, hypoxia-inducible factor.

Table II. Effects of SIRT1 on lipid synthesis.

\begin{tabular}{lll}
\hline Regulation & \multicolumn{1}{c}{ Promoting } & \multicolumn{1}{c}{ Inhibiting } \\
\hline Direct & $\begin{array}{l}\text { Acetic acid is transferred into acetyl-CoA, a key enzyme of lipid } \\
\text { synthesis, under the action of ACSS1 and ACSS2. Deacetylation } \\
\text { by SIRT1 increases the activity of ACSS1 }\end{array}$ & $\begin{array}{l}\text { The complexes of SIRT1 and SIRT6 inhibit } \\
\text { lndirect }\end{array}$ \\
& - & $\begin{array}{l}\text { Inhibits the expression of sterol regulatory } \\
\text { element-binding proteins, increases } \\
\text { the expression of AMP-activated protein kinase. }\end{array}$
\end{tabular}

SIRT, sirtuin; ACSS, acetyl-CoA synthetase.

Table III. Effects of SIRT1 on lipolysis.

\begin{tabular}{llc}
\hline Regulation & \multicolumn{1}{c}{ Promoting } & Inhibiting \\
\hline Direct & - & $\begin{array}{c}\text { The complexes of SIRT1 and SIRT6 increase } \\
\text { lipolysis, providing more energy, and decrease } \\
\text { the use of glycolysis. }\end{array}$ \\
Indirect & $\begin{array}{l}\text { Activates peroxisome proliferator-activated receptor } \gamma \\
\text { coactivator } 1 \alpha \text {; upregulates the level of Forkhead box O1 and } \\
\text { further increases the activity of adipose triglyceride lipase. }\end{array}$ & - \\
\hline
\end{tabular}

SIRT, sirtuin.

and Twist, to encourage local infiltration and distant metastasis (41-43). In addition, SIRT1 decreases the level of matrix metalloproteinases (MMPs) through the TGF $\beta$ pathway, thereby reducing adhesion and connection among epithelial cells and further promoting migration $(43,44)$.

Chemotherapy and radiotherapy are widely used as adjuvant postoperative treatments and they may prognosis. SIRT1 may be involved in resistance to treatment; however, a putative mechanism has not been proposed. The cytotoxic effects of platinum involve the formation of cross-links between double strands of DNA or within a single strand of DNA; the repair of these misconnections require activation of the nucleotide excision repair $(\mathrm{NER})$ pathway $(45,46)$. SIRT1 promotes the phosphorylation of the ATR serine/threonine kinase and further increases the level of cAMP, which can enhance NER (47). Therefore, SIRT1 may be associated with platinum chemoresistance. Additionally, SIRT1 promotes glycolysis to block the cell apoptosis induced by radiotherapy and promotes cancer cell survival (48).

With the emergence of immunosuppressants, such as programmed cell death-1 inhibitors and cytotoxic T-lymphocyte-associated protein-4 inhibitors, immunotherapy 


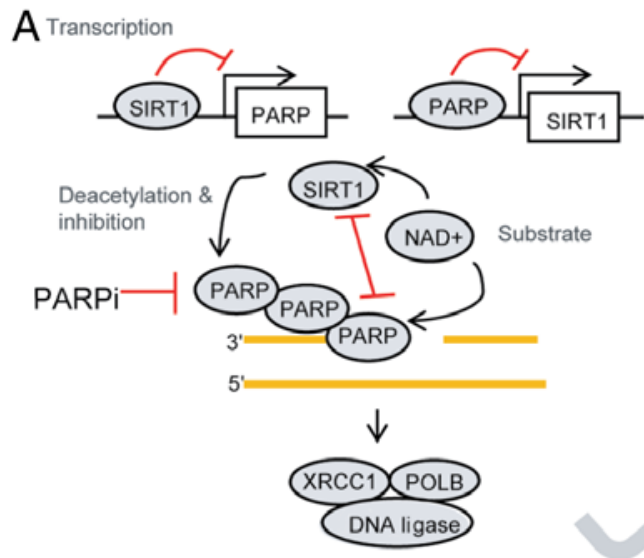

PARPi cause SSBs repair deficiency and DSBs.

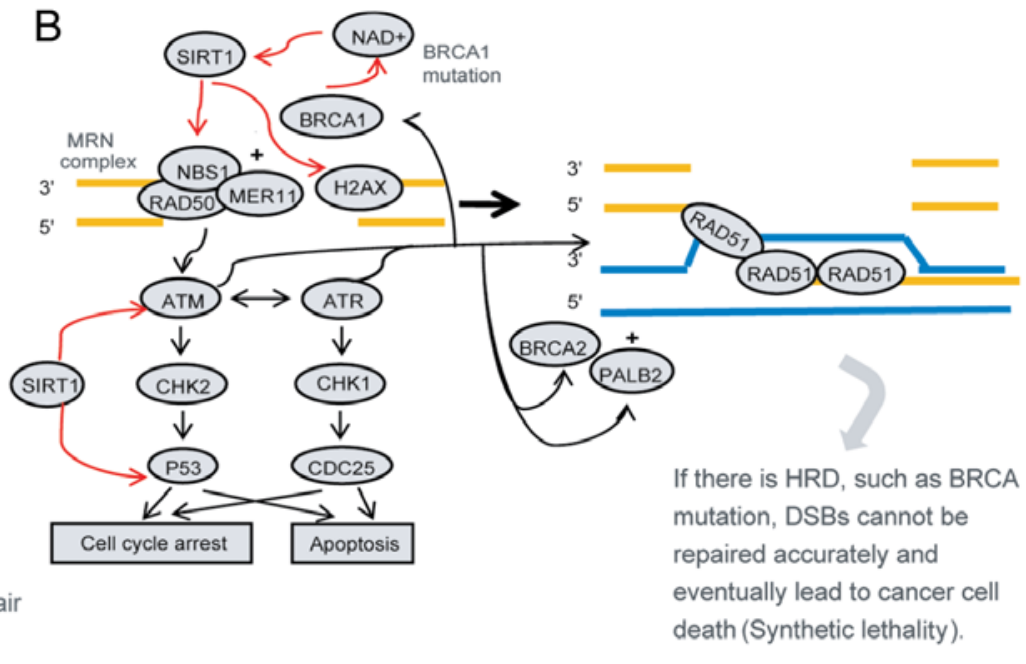

If there is HRD, such as BRCA mutation, DSBs cannot be eventually lead to cancer cell death (Synthetic lethality).

Figure 1. Mechanism of PARPi in the treatment of ovarian cancer and the possible role of SIRT1. Synthetic lethality is the principle of PARPi; i.e., PARPi cause SSB repair defects leading to DSBs. When HRD coexists, a large number of DSBs cannot be repaired or are erroneously repaired, which eventually leads to cancer cell death. (A) SIRT1 interacts with PARP. SIRT1 reduces the level and function of PARP protein through transcription, post-translational modification (deacetylation) and competition for substrates, which may affect the therapeutic effect of PARPi. (B) SIRT1 promotes homologous recombination repair. SIRT1 increases the activity of NBS1, ATM and H2AX through deacetylation and promotes HR. Furthermore, it promotes cell cycle arrest and inhibits apoptosis, which promotes cell survival. When BRCA1 is mutated, HR repair defects may be compensated to some extent by increasing the expression of SIRT1. These findings indicate that SIRT1 may affect the therapeutic efficacy of PARPi. PARPi, poly(ADP-ribose) polymerase inhibitors; SSBs, single-strand breaks; DSBs, double-strand breaks; HRD, homologous recombination deficiency; NAD ${ }^{+}$, nicotinamide adenine dinucleotide; XRCC1, X-ray repair complementing defective repair in Chinese hamster cells 1 ; H2AX, histone H2AX; POLB, DNA polymerase- $\beta$; ATR, ATR serine/threonine kinase; ATM, ATM serine/threonine kinase; CHK1, checkpoint kinase 1; CHK2, checkpoint kinase 2; PALB2, partner and localizer of BRCA2.

has an increasingly important role in the treatment of malignancies (49). The human immune system recognizes and kills tumor cells by a costimulatory signal, but a coinhibitory signal may help these cells escape immune surveillance. Immunosuppressants break inhibitory signals and reactivate the immune system, enabling cytotoxic T lymphocytes (CTLs) to recognize and kill tumor cells $(50,51)$. In addition, cancer cells can expose specific antigens after chemotherapy and other treatments, triggering the immune response, such as recruiting dendritic cells (DCs) and promoting their maturation to present these antigens to CTLs (52-54). Moreover, CTLs can produce a number of inflammatory factors, such as interferon- $\gamma$, and mediate the long-term effects of chemotherapy $(54,55)$. SIRT1 may undermine the immune system and indirectly change the effect of antitumor therapy. Research focused on aging-related diseases has revealed that SIRT1 can limit $N F-\kappa B$ pathway-mediated inflammation and reduce the number of monocytes, which are the precursors of DCs and other cells of the mononuclear phagocytic system (56-58). Other studies have shown that stress increases SIRT1 expression and then changes the glucocorticoid level, which inhibits the body's immune system (34), whereas exogenous administration of glucocorticoids counteracts the antitumor effect of SIRT1 (59).

\section{Role of SIRT1 in gynecological malignancies}

\section{Pathogenic effect}

$E C$. Traditionally, EC is divided into two subtypes based on its histological characteristics (60). Type I EC is endometrioid EC (EEC), accounting for $~ 80 \%$ of all EC cases, whereas the remaining histological patterns, such as serous and clear cell $\mathrm{EC}$, are classified as type II EC.
Researchers have detected significantly higher expression of SIRT1 in EC cells (ECCs) compared with that in normal endometrial cells, indicating that SIRT1 may contribute to the onset of EC $(61,62)$. However, Bartosch et al (63) investigated SIRT1 mRNA and protein expression by quantitative PCR and immunohistochemistry, respectively, in 76 patients with EC and 30 non-EC subjects, and found that SIRT1 mRNA was underexpressed and SIRT1 protein was overexpressed in ECs. Additionally, significantly lower levels of SIRT1 mRNA were found in type II ECs compared with type I ECs, but no significant associations were found between the SIRT1 protein level and the histological subtype, grade, stage, or lymphovascular invasion. These results suggest that the effects of SIRT1 on the pathogenesis of EC are complex. Although the mechanism through which SIRT1 promotes EC remains unclear, there are significant correlations between SIRT1 expression and risk factors for EC.

EECs are estrogen-dependent, as the exposure to a continuous estrogen overload unopposed by progesterone may lead to endometrial hyperplasia, which may evolve into complex atypical hyperplasia and, eventually, progress into cancer $(6,64)$. The ER pathway is the traditional pathway for $17 \beta$-estradiol (E2) (65), which is activated by the binding of $\mathrm{E} 2$ to ER $\alpha$; the E2-ER complexes bind to the promoters of target genes in the nucleus to regulate transcription with the help of coactivators, such as P300, PPAR $\gamma$ and PPAR $\gamma$ coactivator $1 \alpha$, leading to cancer onset and progression (66-68). The ER pathway is also linked to other signaling pathways, such as the EGFR, PI3K and ERK pathways $(69,70)$. In addition to participating in the ER pathway, E2 can also bind to G-protein coupled receptors (GPCRs) to exert similar effects quickly through a non-classical pathway when ER is not expressed (71). 
SIRT1 affects the expression of ER $\alpha$ and the secretion of E2, resulting in the development and maintenance of estrogen-related cancer: E2-ER $\alpha$ complexes promote the expression of SIRT1, which is consistent with the observation that SIRT1 is overexpressed in most ER $\alpha$-positive breast cancer samples (72). In turn, SIRT1 increases the ER $\alpha$ level to enhance the carcinogenic effect of estrogen, forming a positive feedback loop. Similarly, the SIRT1 inhibitor reduces the levels of ER $\alpha$ and interferes with cellular proliferation (73), and E2-GPCR complexes have a parallel function (74). Most importantly, SIRT1 directly facilitates the secretion of E2 by proliferating the expression and function of aromatase (75). However, several studies have indicated that SIRT1 may suppress the function of ER $\alpha(34,76,77)$.

Other risk factors for ECCs are obesity, diabetes and hypertension (6), and the roles of SIRT1 in these diseases have been described in the literature. SIRT1 has been shown to induce mitochondrial-related gene expression and help maintain a healthy weight in mice (78). In animals fed a high-fat, high-sugar diet, SIRT1 improves insulin sensitivity, maintains a normal glucose level in the plasma, and reduces the complications of diabetes $(79,80)$. Insulin secretion is an ATP-dependent process (81), while SIRT1 can increase the level of ATP by inhibiting UCP2 to promote insulin secretion and activate NeuroD and MafA, two transcription factors that promote insulin synthesis $(82,83)$. In addition, SIRT1 can reduce the levels of low-density lipoprotein and cholesterol, increase high-density lipoprotein, obstruct lipid oxidation, platelet aggregation and vascular smooth muscle cell proliferation, and protect cardiovascular cells (84).

Molecular studies have identified PTEN mutation as the most common gene mutation driving EEC, and the PI3K/AKT pathway is known to be affected by PTEN (6). SIRT1 has been shown to inhibit the function of the PTEN protein by deacetylation, thereby activating the PI3K/AKT pathway (85), indicating that SIRT1 may directly promote the development of precancerous lesions.

Type II ECs are usually estrogen-independent, and age is the main risk factor (6). SIRT1 increases the lifespan and resists aging in disparate species, as it is involved in the morphology and function of telomerase (86). p53 acts as a cancer-driving gene in type II ECs (6), while SIRT1 can limit the expression and function of $\mathrm{p} 53$.

Cervical cancer. Close to $100 \%$ of cervical cancer cases are caused by high-risk HPV, with HPV16 and HPV18 being responsible for $70 \%$ of the cases (5). HPV is a small double-stranded DNA virus encoding eight proteins (early stage: E1, E2 and E4-E7; late-stage: L1 and L2), among which E6 and E7 are responsible for progression from cervical intraepithelial neoplasia to cancer $(87,88)$.

SIRT1 is overexpressed in squamous intraepithelial neoplasia and squamous cell carcinoma (SCC), and its expression is increased in advanced illness $(89,90)$. Extensive variation in SIRT1 expression in SCC from low to high suggests that SIRT1 may be an indicator of early lesions (90). Possible causes for the facilitating effect of SIRT1 on cervical cancer are shown in Fig. 2.

SIRT1 cooperates with the E1 and E2 proteins to ensure the quantity and high fidelity of HPV genome replication $(91,92)$.
When infected with HPV, cervical epithelial cells undergo DNA damage, leading to the recruitment of DDR-associated proteins at the E1-E2 binding position in the nucleus and the initiation of HR-dependent replication $(5,87,88)$. SIRT1 is a component of the E1-E2 replication complex and a necessary molecule for initiating replication (91). DDR also stimulates the transcription of SIRT1, which deacetylates Nbs1 and then activates ATM; these processes are followed by the recruitment of the MRN complex and the enhancement of replication. Furthermore, deacetylated Werner helicase displays a greater ability to work with E1 and E2, guaranteeing the fidelity of viral replication (92).

As the downstream target of E7, SIRT1 protects HPV-infected cells from aging and apoptosis $(93,94)$. E6 lowers the level of p53 and further inhibits cell apoptosis, while the expression of retinoblastoma protein (e.g., pRb) is affected by E7; these proteins contribute to cell cycle regulation. Both p53 and $\mathrm{pRb}$ are essential factors for the survival and proliferation of cervical cancer cells $(87,88)$. E7 upregulates SIRT1, and the latter reduces apoptosis by deacetylating target proteins, such as FOXO3 and p53. By contrast, SIRT1 has been shown to be significantly downregulated after E7 knockout, and specific knockout of SIRT1 has been shown to induce tumor cell death $(93,94)$.

SIRT1 may also help infected cells escape innate antiviral immune responses in mammals (95). The overexpression of SIRT1 in tumor cells suppresses the transcription of absent in melanoma 2 (AIM2), a key factor of antiviral immunity, by NF- $\kappa$ B. When SIRT1 is suppressed, the levels of AIM2 and associated inflammasome genes increase and lead to infected cell death through the immune response. Of note, SITR1-knockout cells release vesicles containing AIM2 and inflammasomes, which can be transferred to adjacent cells and cause cell death, demonstrating that the role of SIRT1 is not confined to a single cell.

$O C$. The function of SIRT1 in epithelial OC displays significant heterogeneity. Differentially expressed genes and differential expression network analyses of the ArrayExpress database have revealed that SIRT1 is a hub gene and pathogenic gene for OC (96). Studies based on the Hendrix, GEPIA and Bonome databases show the same expression pattern of SIRT1 (97). However, Kanda et al (98) reported that SIRT1 is upregulated in epithelial $\mathrm{OC}$, and peptide analysis of the plasma verified that the level of SIRT1 precursor is higher in patients with OC compared with that in healthy participants (99).

This heterogeneity may be attributed to tumor components. SIRT1 expression is significantly lower in cancer cells compared with that in stromal cells (100). In tumor cells, SIRT1 deacetylates and inhibits high mobility group box 1, a multifunctional chromosome-related protein that promotes the occurrence and development of OC, which results in the inhibition of metastasis and angiogenesis (101).

In addition, different pathological types of OC may also express varying levels of SIRT1. A study demonstrated that SIRT1 was significantly increased in serous OC (SOC), but its level was not associated with disease stage or grade, suggesting that SIRT1 may facilitate tumorigenesis rather than progression (98). However, another study demonstrated that SOC exhibited the same level of SIRT1 as normal tissues, 


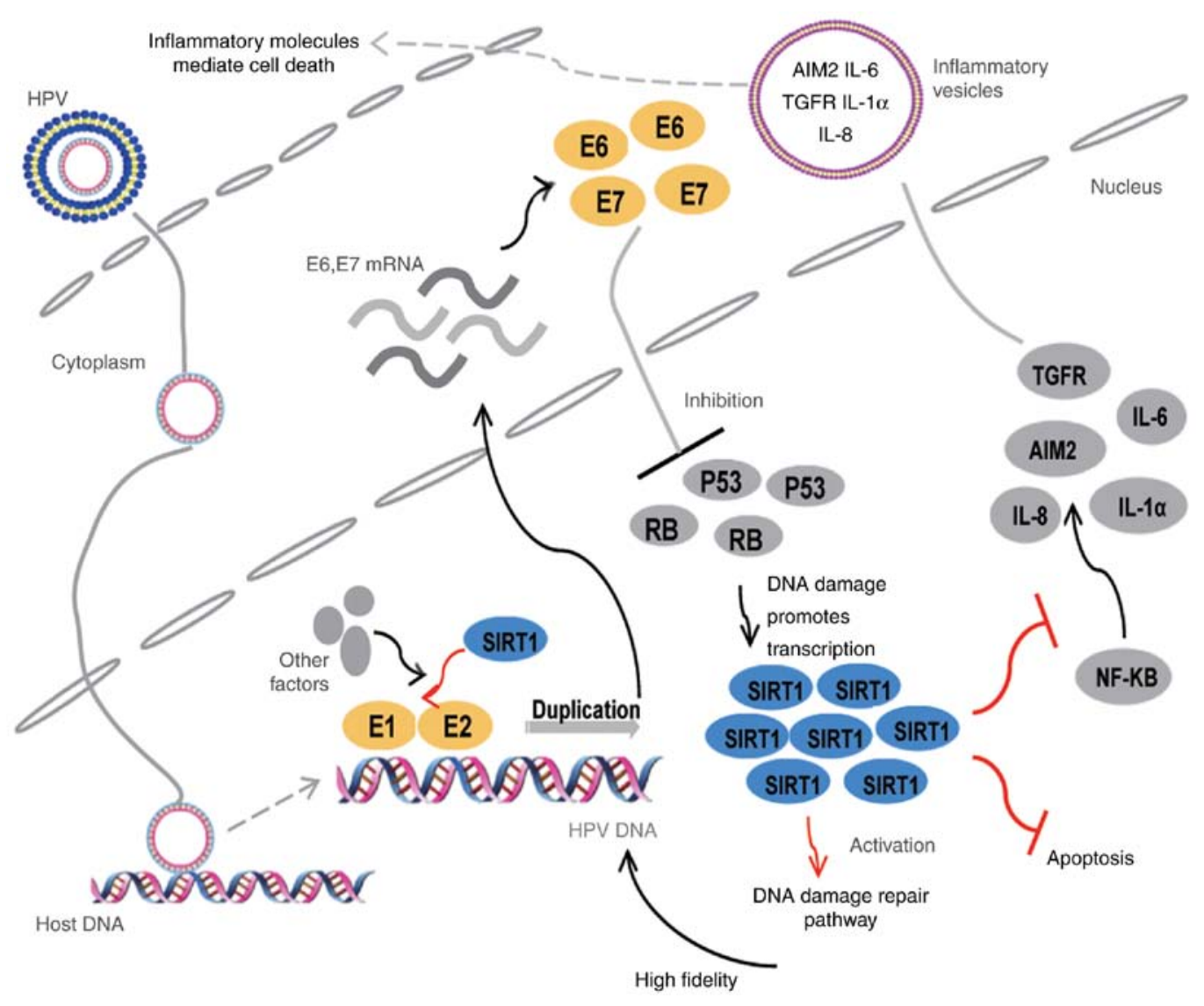

Cervical epithelial cells

Figure 2. SIRT1 promotes persistent HPV infection and malignant transformation of cervical epithelial cells. SIRT1 promotes the onset of cervical cancer as follows: i) As a component of the E1-E2-replicating complex, it participates in the DNA duplication of HPV; ii) HPV infection causes host DNA damage and increases SIRT1 expression, which activates the DNA damage repair process (particularly HR). As a result, high fidelity of HPV DNA replication is ensured; iii) SIRT1 inhibits the apoptosis of infected epithelial cells; iv) SIRT1 decreases the transcription of inflammation-related factors, such as AIM2 and ILs, thereby helping infected cells escape the innate antiviral immunity. HPV, human papillomavirus; AIM2, absent in melanoma 2; IL, interleukin; TGFR, transforming growth factor receptor; NF- $\mathrm{B}$, nuclear factor $\kappa \mathrm{B} ; \mathrm{RB}$, retinoblastoma transcriptional corepressor.

and that this pattern was due to the high mutation frequency of p53 in SOC, which limits the effect of p53 deacetylation on tumor promotion (102). In addition, SIRT1 may be associated with malignant transformation in endometriosis, given its high expression in endometriosis, endometrioid OC and clear cell OC (102). Ovarian sex cord-stromal tumors may also be associated with SIRT1. In granulosa cell tumors, SIRT1 deacylates and inhibits FOXL2, causing cell cycle arrest and DDR, which promotes tumorigenesis, whereas nicotinamide, a SIRT suppressor, inhibits tumor cell proliferation (103). Furthermore, SIRT1 has been shown to be overexpressed in yolk sac cell tumors, which promotes tumor cell proliferation and differentiation and maintains the germ cell state, which may cause recurrence, whereas SIRT1 inhibitors have been shown to inhibit differentiation and invasiveness (104).

\section{Tumor development}

EC. SIRT1 overexpression promotes EC progression, which is inhibited by specific SIRT1 inhibitors (61). As a synthetic inhibitor of histone deacetylase, MHY2256 can significantly decrease SIRT1 levels, thereby increasing the levels and activities of p53, p21 and other cell cycle proteins, which induce autophagy and apoptosis (105). The cancer-promoting effect of SIRT1 may also stem from metabolic changes. SIRT1 can increase the expression of SREBP-1, a nuclear lipogenic transcription factor, and promote the biosynthesis of fatty acids and triglycerides (62). However, miR-29c can bind to the $3^{\prime}$ untranslated region of SIRT1 and inhibit its expression, causing cell death (106); by contrast, OGFRP1, a long non-coding (lnc) RNA, has the capacity to reduce the production of miR-124-3p and further increase the level of SIRT1 in cancer cells, thereby promoting invasion and metastasis of ECs (107).

Cervical cancer. SIRT1 promotes the metastasis of cervical cancer. A decrease in miR-29 in malignant cells can reduce SIRT1 transcriptional suppression; the resulting increased levels of SIRT1 can promote EMT by increasing the expression and activity of MMP9 and enhancing cell migration and invasion $(108,109)$. The lncRNA TUG1, which is upregulated in cancer cells and may act as a molecular sponge, can bind to miR-138-5p and amplify SIRT1, leading to cell proliferation via the Wnt/ $\beta$-catenin pathway (110), whereas the overexpression of miR-138-5p can inhibit the transcription of SIRT1 and further arrest cells in the G0/G1 phase, thereby inducing apoptosis (111). However, it has been shown that, when pyruvate augments the binding between the histone gene promoter and SIRT1, heterochromatin density and genome imbalance suppress cell proliferation (112). 
$O C$. SIRT1 plays a dual role in OC metastasis. SIRT1 may promote tumor metastasis. The deacetylation of cortactin mediated by SIRT1 increases the expression of vimentin, a mesenchymal cell marker, and reduces that of E-cadherin, an epithelial cell marker, thereby promoting EMT and tumor cell migration $(113,114)$. SIRT1 expression has been shown to be correlated with ER expression and to impact the effect of E2-ER complexes on EMT (115). Amyotrophic lateral sclerosis, hypoxia and 15d-PGJ2 induce apoptosis and reduce the migration of cells due to the reduced levels of SIRT1 (116-118). However, other research has indicated that higher levels of SIRT1 in OC suppress invasion and metastasis by increasing the epithelial phenotype (119). SIRT1 deacetylates and activates KLF4, which binds to the CLDN5 promoter to maintain the characteristics of epithelial cells (120). SIRT1 can also lower the EMT-inducing zinc finger E-box binding homeobox 1 by deacetylating hypoxia-inducible factor (HIF) $1 \alpha$ (121). Rikkunshito, a Japanese herbal medicine, can decrease EMT by stimulating the expression of SIRT1 (98).

SIRT1 also has opposing roles in OC cell proliferation. SIRT1 reduces the levels of reactive oxygen species, promoting tumor cell proliferation and reducing apoptosis (122). miR-494 and artesunate accelerate cell death by downregulating SIRT1 (123,124). Additionally, 15-deoxy- $\Delta 12,14$-prostaglandin J2, a SIRT1 inhibitor, and its derivatives exert anticancer effects by blocking the cell cycle and triggering apoptosis and autophagy (125). Calorie restriction and metformin have been shown to increase the expression of SIRT1 in a mouse model and cause significant decreases in the tumor load in the peritoneum, liver, kidney, spleen and intestine; furthermore, growth factors, such as insulin-like growth factor-1, insulin, interleukin-1, monocyte chemoattractant protein-1 and vascular endothelial growth factor, in the plasma and ascitic fluid have been found to decrease the expression of SIRT1 $(126,127)$.

\section{Treatment}

$E C$. Chemotherapy is a crucial method for the postoperative adjuvant therapy of EC, and SIRT1 is closely associated with platinum and paclitaxel resistance (61). Progesterone therapy is another common adjuvant treatment; it is used mainly as conservative treatment of patients who wish to preserve their fertility and as adjuvant treatment for patients with advanced disease (6). Researchers have found that SIRT1 is overexpressed in medroxyprogesterone acetate (MPA)-resistant tumors and that the level of progesterone receptor (PR) expression is decreased in those tumors (128). It has been found that, after SIRT1 is knocked out, the levels of PR are restored and tumor sensitivity to MPA is recovered, indicating that SIRT1 participates in progesterone resistance.

Cervical cancer. SIRT1 has been shown to increase multidrug resistance-associated protein (MRP) expression on the cell membrane, inducing chemotherapy resistance in paclitaxel-resistant tumor cells (129). In addition, SIRT1 is partly responsible for the transformation of chemoresistance, as it transfers deacetylated FOXO1 and ATP-binding cassette transporter p-glycoprotein and MRP to neighboring cells (130). Moreover, SIRT1 induces p53-dependent chemoresistance by p53 deacetylation; for example, the response to doxorubicin was shown to be restored in SIRT1-knockout cells (131).
Surgery after two to three cycles of neoadjuvant chemotherapy (NACT) is an alternative treatment for patients with locally advanced cervical cancer whose tumors are too large to operate or are at an inoperable stage (3). Currently, clinicians lack predictive indicators for evaluating NACT efficiency; therefore, disease progression during NACT may occur in some patients. SIRT1 may be used as such a predictor. Teramae et al (132) divided patients with locally advanced cervical cancer who had received NACT into two groups based on the level of SIRT1; the weighted score of the low group was $\leq 4$, whereas that of the high group was $\geq 6$. They found that the patients in the low-SIRT1 group significantly benefited from NACT, indicating that an elevated SIRT1 level is a negative indicator of NACT.

$O C$. SIRT1 is highly expressed in SOC patients with chemoresistance. Its high expression in these patients is due to its stimulating effect on MRP $(133,134)$. Cancer stem cells (CSCs) are a possible source of drug resistance and a cause of relapse in malignant tumors. Researchers have found that the percentage of $\mathrm{EpCAM}^{+} \mathrm{CD} 45^{+}(\mathrm{CSC}$ potential surface marker) cells in ascites is increased in patients with high-SIRT1 expression, and that hypoxia increases SIRT1 levels by affecting HIF $\alpha$ and NF- $\mathrm{BB}$, thereby maintaining the stemness characteristics of CSCs (135). Following exposure to cytotoxic drugs, intracellular SIRT1 levels have been shown to be upregulated and to further improve the transcription of stemness-associated genes, leading to acquired chemotherapy resistance (114).

Recently, PARPi, which cause defects in single-strand break repair, have become the most promising targeted drugs for $\mathrm{OC}$ and were recommended by the National Comprehensive Cancer Network guidelines as first-line maintenance therapy (136). PARPi kill tumor cells when HR defects exist, of which the BRCA mutation is the most common, also known as 'synthetic lethality' (Fig. 1) (137). Moreover, the damage caused by the continuous binding of PARP-PARPi to DNA is far more lethal than the reduction in PARP protein; therefore, the amount and function of PARP proteins are crucial for PARPi efficacy (138). SIRT1 may suppress the synthesis and function of PARP (139) and impair the therapeutic effect of PARPi (Fig. 1). As both PARP and SIRT1 require $\mathrm{NAD}^{+}$, they have a competitive relationship. SIRT1 can post-translationally modify PARP and affect its function; when overexpressed, SIRT1 can deacetylate PARP-1 and inhibit its function; SIRT1 can also specifically bind to the promoter of PARP and inhibit its transcription. In addition, SIRT1 promotes HR repair and impedes PARPi (Fig. 1). Notably, the loss of the BRCA1 function increases $\mathrm{NAD}^{+}$synthesis and SIRT1 activity, suggesting that SIRT1 may partially compensate for the HR repair effect when BRCA1 is defective (140).

Prognosis. There is abundant evidence suggesting that SIRT1 overexpression is responsible for poor prognosis in EC (61), cervical cancer $(95,108,110)$ and OC $(97,98,102)$. After HPV infection of cervical epithelial cells, increased SIRT1 expression is closely associated with poor prognosis. Similarly, decreases in miR-29a and miR-138-5p levels lead to an increase in SIRT1 levels and poor prognosis. High levels of 
SIRT1 in OC, particularly SOC, are associated with reductions in the progression-free and overall survival of patients with OC.

\section{Conclusions}

The present review summarized the possible pathogenic role of SIRT1 in malignant tumors, which involves DDR and metabolism. The articles included in this review were focused on different pathways and factors. As a result, SIRT1 was shown to serve a dual role in cancer promotion as well as cancer suppression. In addition, the functions of SIRT1 in non-gynecological malignancies are discussed in the present review, and exhibit tissue specificity. Furthermore, in this review, the possible roles of SIRT1 in the occurrence, development and treatment of gynecological malignancies were discussed. Although the role of SIRT1 in the pathogenesis of cervical cancer has been elucidated, further research is needed to understand the mechanisms underlying the involvement of SIRT1 in EC and OC. SIRT1 is associated with multiple risk factors for EC, such as high estrogen levels, hypertension, metabolic syndrome, driving mutations, and disruptions in certain signaling pathways; we herein aimed to summarize gaps in research and identify topics for further research. Additionally, SIRT1 is associated with the invasiveness, metastasis and treatment resistance of tumors. Therefore, SIRT1 may serve as an indicator of poor prognosis and as a target for cancer treatment. Most importantly, we herein highlighted the ability of SIRT1 to interact with PARPi. Since SIRT1 counteracts the therapeutic effect of PARPi, it was hypothesized that SIRT1 inhibitors may act synergistically with PARPi; however, the application of PARPi and SIRT1 inhibitors in OC requires further investigation. Finally, although SIRT1 is involved in the stemness regulation of CSCs, no articles on the niche of CSCs and SIRT1 were found. However, we observed that the role of SIRT1 in the CSC niche had become a research hotspot for other types of cancer, such as breast, lung and gastrointestinal cancer; therefore, it may represent a promising topic for future research in the field of gynecological oncology.

\section{Acknowledgements}

Not applicable.

\section{Funding}

This project was supported by CAMS Innovation Fund for Medical Sciences (grant no. CIFMS-2017-I2M-1-002) and by the Fund of The National Key R\&D Program of China 2016YFC1303700 (affiliated project 2016YFC1303701).

\section{Availability of data and materials}

The data that support the findings of the present study are available from the corresponding author upon reasonable request.

\section{Authors' contributions}

JC, LP and HC equally contributed to the study conception and design and material preparation. The first draft of the manuscript was written by JC, and all authors have critically revised the manuscript for important intellectual content. All the authors have read and approved the final manuscript.

\section{Ethics approval and consent to participate}

Not applicable.

\section{Patient consent for publication}

Not applicable.

\section{Competing interests}

The authors declare that they have no competing interests.

\section{References}

1. Siegel RL, Miller KD and Jemal A: Cancer statistics, 2019. CA Cancer J Clin 69: 7-34, 2019.

2. Vaccarella S, Lortet-Tieulent J, Plummer M, Franceschi S and Bray F: Worldwide trends in cervical cancer incidence: Impact of screening against changes in disease risk factors. Eur J Cancer 49: 3262-3273, 2013.

3. WHO. Cervical cancer. World Health Organization: Geneva, 2018. http://www.who.int/cancer/prevention/diagnosis-screening/cervical-cancer/en. Accessed January 10, 2020.

4. Chen W, Zheng R, Baade PD, Zhang S, Zeng H, Bray F, Jemal A, Yu XQ and He J: Cancer statistics in China, 2015. CA Cancer J Clin 66: 115-132, 2016.

5. Cohen PA, Jhingran A, Oaknin A and Denny L: Cervical cancer. Lancet 393: 169-182, 2019.

6. Morice P, Leary A, Creutzberg C, Abu-Rustum N and Darai E: Endometrial cancer. Lancet 387: 1094-1108, 2016.

7. Lheureux S, Gourley C, Vergote I and Oza AM: Epithelial ovarian cancer. Lancet 393: 1240-1253, 2019.

8. Nogueiras R, Habegger KM, Chaudhary N, Finan B, Banks AS, Dietrich MO, Horvath TL, Sinclair DA, Pfluger PT and Tschöp MH: Sirtuin 1 and sirtuin 3: Physiological modulators of metabolism. Physiol Rev 92: 1479-1514, 2012.

9. Michishita E, Park JY, Burneskis JM, Barrett JC and Horikawa I: Evolutionarily conserved and nonconserved cellular localizations and functions of human SIRT proteins. Mol Biol Cell 16: 4623-4635, 2005.

10. Morris BJ: Seven sirtuins for seven deadly diseases of aging. Free Radic Biol Med 56: 133-171, 2013.

11. Bitterman KJ, Anderson RM, Cohen HY, Latorre-Esteves M and Sinclair DA: Inhibition of silencing and accelerated aging by nicotinamide, a putative negative regulator of yeast sir 2 and human SIRT1. J Biol Chem 277: 45099-45107, 2002.

12. Guarente L: Franklin H: Epstein lecture: Sirtuins, aging, and medicine. N Engl J Med 364: 2235-2244, 2011.

13. Alves-Fernandes DK and Jasiulionis MG: The role of SIRT1 on DNA damage response and epigenetic alterations in cancer. Int J Mol Sci 20: 3153, 2019.

14. O'Hagan HM: Chromatin modifications during repair of environmental exposure-induced DNA damage: A potential mechanism for stable epigenetic alterations. Environ Mol Mutagen 55: 278-291, 2014.

15. Ura K, Araki M, Saeki H, Masutani C, Ito $T$, Iwai $S$, Mizukoshi T, Kaneda Y and Hanaoka F: ATP-dependent chromatin remodeling facilitates nucleotide excision repair of UV-induced DNA lesions in synthetic dinucleosomes. EMBO J 20: 2004-2014, 2001.

16. Kala R, Shah HN, Martin SL and Tollefsbol TO: Epigenetic-based combinatorial resveratrol and pterostilbene alters DNA damage response by affecting SIRT1 and DNMT enzyme expression, including SIRT1-dependent $\gamma$-H2AX and telomerase regulation in triple-negative breast cancer. BMC Cancer 15: 672, 2015.

17. Ding N, Bonham EM, Hannon BE, Amick TR, Baylin SB and O'Hagan HM: Mismatch repair proteins recruit DNA methyltransferase 1 to sites of oxidative DNA damage. J Mol Cell Biol 8: 244-254, 2016. 
18. Deng CX: SIRT1, is it a tumor promoter or tumor suppressor? Int J Biol Sci 5: 147-152, 2009.

19. Dobbin MM, Madabhushi R, Pan L, Chen Y, Kim D, Gao J, Ahanonu B, Pao PC, Qiu Y, Zhao Y and Tsai LH: SIRT1 collaborates with ATM and HDAC1 to maintain genomic stability in neurons. Nat Neurosci 16: 1008-1015, 2013.

20. Ong ALC and Ramasamy TS: Role of Sirtuin1-p53 regulatory axis in aging, cancer and cellular reprogramming. Ageing Res Rev 43: 64-80, 2018.

21. Guarente L: Sirtuins in aging and disease. Cold Spring Harb Symp Quant Biol 72: 483-488, 2007.

22. Currie E, Schulze A, Zechner R, Walther TC and Farese RV Jr: Cellular fatty acid metabolism and cancer. Cell Metab 18 153-161, 2013.

23. Hamanaka RB and Chandel NS: Targeting glucose metabolism for cancer therapy. J Exp Med 209: 211-215, 2012.

24. Maan M, Peters JM, Dutta M and Patterson AD: Lipid metabolism and lipophagy in cancer. Biochem Biophys Res Commun 504: 582-589, 2018.

25. Warburg O, Wind $\mathrm{F}$ and Negelein E: The metabolism of tumors in the body. J Gen Physiol 8: 519-530, 1927.

26. Warburg O: On the origin of cancer cells. Science 123: 309-314, 1956.

27. Kleszcz R, Paluszczak J and Baer-Dubowska W: Targeting aberrant cancer metabolism - The role of sirtuins. Pharmacol Rep 67: 1068-1080, 2015

28. Vander Heiden MG, Cantley LC and Thompson CB: Understanding the Warburg effect: The metabolic requirements of cell proliferation. Science 324: 1029-1033, 2009.

29. Taylor DM, Maxwell MM, Luthi-Carter R and Kazantsev AG: Biological and potential therapeutic roles of sirtuin deacetylases. Cell Mol Life Sci 65: 4000-4018, 2008.

30. Haigis MC and Guarente LP: Mammalian sirtuins-emerging roles in physiology, aging, and calorie restriction. Genes Dev 20: 2913-2921, 2006.

31. Chalkiadaki A and Guarente L: The multifaceted functions of sirtuins in cancer. Nat Rev Cancer 15: 608-624, 2015

32. Ye X, Li M, Hou T, Gao T, Zhu WG and Yang Y: Sirtuins in glucose and lipid metabolism. Oncotarget 8: 1845-1859, 2017.

33. Zhu S, Dong Z, Ke X, Hou J, Zhao E, Zhang K, Wang F, Yang L, Xiang Z and Cui $\mathrm{H}$ : The roles of sirtuins family in cell metabolism during tumor development. Semin Cancer Biol 57: 59-71, 2019.

34. Moore RL, Dai Y and Faller DV: Sirtuin 1 (SIRT1) and steroid hormone receptor activity in cancer. J Endocrinol 213: 37-48, 2012.

35. Zhong J, Ji L, Chen H, Li X, Zhang J, Wang X, Wu W, Xu Y, Huang F, Cai W and Sun ZS: Acetylation of hMOF modulates $\mathrm{H} 4 \mathrm{~K} 16 \mathrm{ac}$ to regulate DNA repair genes in response to oxidative stress. Int J Biol Sci 13: 923-934, 2017.

36. Shah NP, Nicoll JM, Nagar B, Gorre ME, Paquette RL, Kuriyan J and Sawyers CL: Multiple BCR-ABL kinase domain mutations confer polyclonal resistance to the tyrosine kinase inhibitor imatinib (STI571) in chronic phase and blast crisis chronic myeloid leukemia. Cancer Cell 2: 117-125, 2002

37. Roth M, Wang Z and Chen WY: SIRT1 and LSD1 competitively regulate KU70 functions in DNA repair and mutation acquisition in cancer cells. Oncotarget 7: 50195-50214, 2016.

38. Jeong J, Juhn K, Lee H, Kim SH, Min BH, Lee KM, Cho MH Park GH and Lee KH: SIRT1 promotes DNA repair activity and deacetylation of Ku70. Exp Mol Med 39: 8-13, 2007.

39. Byles V, Zhu L, Lovaas JD, Chmilewski LK, Wang J, Faller DV and Dai Y: SIRT1 induces EMT by cooperating with EMT transcription factors and enhances prostate cancer cell migration and metastasis. Oncogene 31: 4619-4629, 2012

40. Simic P, Williams EO, Bell EL, Gong JJ, Bonkowski M and Guarente L: SIRT1 suppresses the epithelial-to-mesenchymal transition in cancer metastasis and organ fibrosis. Cell Rep 3: $1175-1186,2013$

41. Nakopoulou L, Tsirmpa I, Alexandrou P, Louvrou A, Ampela C, Markaki S and Davaris PS: MMP-2 protein in invasive breast cancer and the impact of MMP-2/TIMP-2 phenotype on overall survival. Breast Cancer Res Treat 77: 145-155, 2003.

42. Abdelmawgoud $\mathrm{H}$ and El Awady RR: Effect of Sirtuin 1 inhibition on matrix metalloproteinase 2 and Forkhead box O3a expression in breast cancer cells. Genes Dis 4: 240-246, 2017.

43. Shi L, Tang X, Qian M, Liu Z, Meng F, Fu L, Wang Z, Zhu WG, Huang JD, Zhou Z and Liu B: A SIRT1-centered circuitry regulates breast cancer stemness and metastasis. Oncogene 37: 6299-6315, 2018
44. García-Vizcaíno EM, Liarte S, Alonso-Romero JL and Nicolás FJ: Sirt1 interaction with active Smad2 modulates transforming growth factor- $\beta$ regulated transcription. Cell Commun Signal 15: 50, 2017.

45. KellandL:Theresurgence of platinum-basedcancerchemotherapy. Nat Rev Cancer 7: 573-584, 2007.

46. Ceccaldi R, O'Connor KW, Mouw KW, Li AY, Matulonis UA, D'Andrea AD and Konstantinopoulos PA: A unique subset of epithelial ovarian cancers with platinum sensitivity and PARP inhibitor resistance. Cancer Res 75: 628-634, 2015.

47. Jarrett SG, Carter KM, Bautista RM, He D, Wang C and D'Orazio JA: Sirtuin 1-mediated deacetylation of XPA DNA repair protein enhances its interaction with ATR protein and promotes cAMP-induced DNA repair of UV damage. J Biol Chem 293: 19025-19037, 2018.

48. Joo HY, Woo SR, Shen YN, Yun MY, Shin HJ, Park ER, Kim SH, Park JE, Ju YJ, Hong SH, et al: SIRT1 interacts with and protects glyceraldehyde-3-phosphate dehydrogenase (GAPDH) from nuclear translocation: Implications for cell survival after irradiation. Biochem Biophys Res Commun 424: 681-686, 2012.

49. Esfahani K, Roudaia L, Buhlaiga N, Del Rincon SV, Papneja N and Miller WH Jr: A review of cancer immunotherapy: From the past, to the present, to the future. Curr Oncol 27 (Suppl 2): S87-S97, 2020

50. Van Coillie S, Wiernicki B and Xu J: Molecular and cellular functions of CTLA-4. Adv Exp Med Biol 1248: 7-32, 2020.

51. Han Y, Liu D and Li L: PD-1/PD-L1 pathway: Current researches in cancer. Am J Cancer Res 10: 727-742, 2020.

52. Galluzzi L, Buqué A, Kepp O, Zitvogel L and Kroemer G: Immunological effects of conventional chemotherapy and targeted anticancer agents. Cancer Cell 28: 690-714, 2015.

53. Ma Y, Adjemian S, Mattarollo SR, Yamazaki T, Aymeric L, Yang H, Portela Catani JP, Hannani D, Duret H, Steegh K, et al: Anticancer chemotherapy-induced intratumoral recruitment and differentiation of antigen-presenting cells. Immunity 38: 729-741, 2013.

54. Ma Y,Pitt JM,Li Q and Yang $\mathrm{H}$ : The renaissance of anti-neoplastic immunity from tumor cell demise. Immunol Rev 280: 194-206, 2017.

55. Vacchelli E, Ma Y, Baracco EE, Sistigu A, Enot DP, Pietrocola F, Yang H, Adjemian S, Chaba K, Semeraro M, et al: Chemotherapy-induced antitumor immunity requires formyl peptide receptor 1. Science 350: 972-978, 2015.

56. Morris BJ: Seven sirtuins for seven deadly diseases of aging. Free Radic Biol Med 56: 133-171, 2013.

57. Qureshi AA, Guan XQ, Reis JC, Papasian CJ, Jabre S, Morrison DC and Qureshi N: Inhibition of nitric oxide and inflammatory cytokines in LPS-stimulated murine macrophages by resveratrol, a potent proteasome inhibitor. Lipids Health Dis 11: 76, 2012.

58. Lanzilli G, Cottarelli A, Nicotera G, Guida S, Ravagnan G and Fuggetta MP: Anti-inflammatory effect of resveratrol and polydatin by in vitro IL-17 modulation. Inflammation 35: 240-248, 2012.

59. Yang H, Xia L, Chen J, Zhang S, Martin V, Li Q, Lin S, Chen J, Calmette J, Lu M, et al: Stress-glucocorticoid-TSC22D3 axis compromises therapy-induced antitumor immunity. Nat Med 25: 1428-1441, 2019

60. Bokhman JV: Two pathogenetic types of endometrial carcinoma. Gynecol Oncol 15: 10-17, 1983.

61. Asaka R, Miyamoto T, Yamada Y, Ando H, Mvunta DH, Kobara $\mathrm{H}$ and Shiozawa T: Sirtuin 1 promotes the growth and cisplatin resistance of endometrial carcinoma cells: A novel therapeutic target. Lab Invest 95: 1363-1373, 2015.

62. Lin L, Zheng X, Qiu C, Dongol S, Lv Q, Jiang J, Kong B and Wang C: SIRT1 promotes endometrial tumor growth by targeting SREBP1 and lipogenesis. Oncol Rep 32: 2831-2835, 2014.

63. Bartosch C, Monteiro-Reis S, Almeida-Rios D, Vieira R, Castro A, Moutinho M, Rodrigues M, Graça I, Lopes JM and Jerónimo C: Assessing sirtuin expression in endometrial carcinoma and non-neoplastic endometrium. Oncotarget 7: 1144-1154, 2016.

64. Huang P, Chandra V and Rastinejad F: Structural overview of the nuclear receptor superfamily: Insights into physiology and therapeutics. Annu Rev Physiol 72: 247-272, 2010.

65. Burns KA and Korach KS: Estrogen receptors and human disease: An update. Arch Toxicol 86: 1491-1504, 2012.

66. Sanchez R, Nguyen D, Rocha W, White JH and Mader S: Diversity in the mechanisms of gene regulation by estrogen receptors. Bioessays 24: 244-254, 2002. 
67. Weigel NL and Zhang Y: Ligand-independent activation of steroid hormone receptors. J Mol Med (Berl) 76: 469-479, 1998.

68. Cenni B and Picard D: Ligand-independent activation of steroid receptors: New roles for old players. Trends Endocrinol Metab 10: 41-46, 1999.

69. Kinyamu HK and Archer TK: Modifying chromatin to permit steroid hormone receptor-dependent transcription. Biochim Biophys Acta 1677: 30-45, 2004.

70. Perissi V and Rosenfeld MG: Controlling nuclear receptors: The circular logic of cofactor cycles. Nat Rev Mol Cell Biol 6 : 542-554, 2005.

71. Filardo EJ, Quinn JA, Bland KI and Frackelton AR Jr: Estrogen-induced activation of Erk-1 and Erk-2 requires the $\mathrm{G}$ protein-coupled receptor homolog, GPR30, and occurs via trans-activation of the epidermal growth factor receptor through release of HB-EGF. Mol Endocrinol 14: 1649-1660, 2000.

72. Elangovan S, Ramachandran S, Venkatesan N, Ananth S, Gnana-Prakasam JP, Martin PM, Browning DD, Schoenlein PV, Prasad PD, Ganapathy V and Thangaraju M: SIRT1 is essential for oncogenic signaling by estrogen/estrogen receptor $\alpha$ in breast cancer. Cancer Res 71: 6654-6664, 2011.

73. Yao Y, Li H, Gu Y, Davidson NE and Zhou Q: Inhibition of SIRT1 deacetylase suppresses estrogen receptor signaling. Carcinogenesis 31: 382-387, 2010

74. Santolla MF, Avino S, Pellegrino M, De Francesco EM, De Marco P, Lappano R, Vivacqua A, Cirillo F, Rigiracciolo DC, Scarpelli A, et al: SIRT1 is involved in oncogenic signaling mediated by GPER in breast cancer. Cell Death Dis 6: el834, 2015.

75. Holloway KR, Barbieri A, Malyarchuk S, Saxena M Nedeljkovic-Kurepa A, Cameron Mehl M, Wang A, Gu X and Pruitt K: SIRT1 positively regulates breast cancer associated human aromatase (CYP19A1) expression. Mol Endocrinol 27: 480-490, 2013.

76. Kim MY, Woo EM, Chong YT, Homenko DR and Kraus WL: Acetylation of estrogen receptor alpha by p300 at lysines 266 and 268 enhances the deoxyribonucleic acid binding and transactivation activities of the receptor. Mol Endocrinol 20: 1479-1493, 2006.

77. Xu Z, Yang Y, Li B, Li Y, Xia K, Yang Y, Li X, Wang M, Li S and $\mathrm{Wu} \mathrm{H}$ : Checkpoint suppressor 1 suppresses transcriptional activity of $\mathrm{ER} \alpha$ and breast cancer cell proliferation via deacetylase SIRT1. Cell Death Dis 9: 559, 2018.

78. Price NL, Gomes AP, Ling AJ, Duarte FV, Martin-Montalvo A, North BJ, Agarwal B, Ye L, Ramadori G, Teodoro JS, et al SIRT1 is required for AMPK activation and the beneficial effects of resveratrol on mitochondrial function. Cell Metab 15 675-690, 2012

79. Baur JA, Pearson KJ, Price NL, Jamieson HA, Lerin C, Kalra A, Prabhu VV, Allard JS, Lopez-Lluch G, Lewis K, et al: Resveratro improves health and survival of mice on a high-calorie diet. Nature 444: 337-342, 2006

80. Baur JA and Sinclair DA: Therapeutic potential of resveratrol: The in vivo evidence. Nat Rev Drug Discov 5: 493-506, 2006.

81. Moynihan KA, Grimm AA, Plueger MM, Bernal-Mizrachi E, Ford E, Cras-Méneur C, Permutt M and Imai S: Increased dosage of mammalian Sir2 in pancreatic beta cells enhances glucose-stimulated insulin secretion in mice. Cell Metab 2: 105-117, 2005.

82. Bordone L, Motta MC, Picard F, Robinson A, Jhala US, Apfeld J, McDonagh T, Lemieux M, McBurney M, Szilvasi A, et al: Sirtl regulates insulin secretion by repressing UCP2 in pancreatic beta cells. PLoS Biol 4: e31, 2006.

83. Kitamura YI, Kitamura T, Kruse JP, Raum JC, Stein R, Gu W and Accili D: FoxO1 protects against pancreatic beta cell failure through NeuroD and MafA induction. Cell Metab 2: 153-163, 2005.

84. Fontana L, Meyer TE, Klein S and Holloszy JO: Long-term calorie restriction is highly effective in reducing the risk for atherosclerosis in humans. Proc Natl Acad Sci USA 101: 6659-6663, 2004.

85. Ikenoue T, Inoki K, Zhao B and Guan KL: PTEN acetylation modulates its interaction with PDZ domain. Cancer Res 68: 6908-6912, 2008.

86. Hubbard BP and Sinclair DA: Small molecule SIRT1 activators for the treatment of aging and age-related diseases. Trends Pharmacol Sci 35: 146-154, 2014.

87. Vonsky M, Shabaeva M, Runov A, Lebedeva N, Chowdhury S, Palefsky JM and Isaguliants M: Carcinogenesis associated with human papillomavirus infection. Mechanisms and potential for immunotherapy. Biochemistry (Mosc) 84: 782-799, 2019.
88. Almeida AM, Queiroz JA, Sousa F and Sousa Â: Cervical cancer and HPV infection: Ongoing therapeutic research to counteract the action of E6 and E7 oncoproteins. Drug Discov Today 24: 2044-2057, 2019.

89. Velez-Perez A, Wang XI, Li M and Zhang S: SIRT1 overexpression in cervical squamous intraepithelial lesions and invasive squamous cell carcinoma. Hum Pathol 59: 102-107, 2017.

90. Singh S, Kumar PU, Thakur S, Kiran S, Sen B, Sharma S, Rao VV, Poongothai AR and Ramakrishna G: Expression/localization patterns of sirtuins (SIRT1, SIRT2, and SIRT7) during progression of cervical cancer and effects of sirtuin inhibitors on growth of cervical cancer cells. Tumour Biol 36: 6159-6171, 2015.

91. Das D, Smith N, Wang X and Morgan IM: The deacetylase SIRT1 regulates the replication properties of human papillomavirus $16 \mathrm{E} 1$ and E2. J Virol 91: e00102-17, 2017.

92. Das D, Bristol ML, Smith NW, James CD, Wang X, Pichierri P and Morgan IM: Werner helicase control of human papillomavirus 16 E1-E2 DNA replication is regulated by SIRT1 deacetylation. mBio 10: e00263-19, 2019.

93. Allison SJ, Jiang M and Milner J: Oncogenic viral protein HPV E7 up-regulates the SIRT1 longevity protein in human cervical cancer cells. Aging (Albany NY) 1: 316-327, 2009.

94. Brooks CL and Gu W: Anti-aging protein SIRT1: A role in cervical cancer? Aging (Albany NY) 1: 278-280, 2009.

95. So D, Shin HW, Kim J, Lee M, Myeong J, Chun YS and Park JW: Cervical cancer is addicted to SIRT1 disarming the AIM2 antiviral defense. Oncogene 37: 5191-5204, 2018.

96. Lu X, Wang J, Shan X and Li Y: Selecting key genes associated with ovarian cancer based on differential expression network J BUON 22: 48-57, 2017

97. Sun X, Wang S and Li Q: Comprehensive analysis of expression and prognostic value of sirtuins in ovarian cancer. Front Genet 10: 879, 2019.

98. Kanda R, Miyagawa Y, Wada-Hiraike O, Hiraike H, Fukui S, Nagasaka K, Ryo E, Fujii T, Osuga Y and Ayabe T: Rikkunshito attenuates induction of epithelial-mesenchymal switch via activation of Sirtuin1 in ovarian cancer cells. Endocr J 67: 379-386, 2020.

99. Dufresne J, Bowden P, Thavarajah T, Florentinus-Mefailoski A Chen ZZ, Tucholska M, Norzin T, Ho MT, Phan M, Mohamed N, et al: The plasma peptides of ovarian cancer. Clin Proteomics 15: 41, 2018.

100. Shin DH, Choi YJ, Jin P, Yoon H, Chun YS, Shin HW, Kim JE and Park JW: Distinct effects of SIRT1 in cancer and stromal cells on tumor promotion. Oncotarget 7: 23975-23987, 2016

101. Jiang W, Jiang P, Yang R and Liu DF: Functional role of SIRT1-induced HMGB1 expression and acetylation in migration, invasion and angiogenesis of ovarian cancer. Eur Rev Med Pharmacol Sci 22: 4431-4439, 2018

102. Mvunta DH, Miyamoto T, Asaka R, Yamada Y, Ando H, Higuchi S, Ida K, Kashima $\mathrm{H}$ and Shiozawa T: Overexpression of SIRT1 is associated with poor outcomes in patients with ovarian carcinoma. Appl Immunohistochem Mol Morphol 25: 415-421, 2017.

103. Benayoun BA, Georges AB, L'Hôte D, Andersson N, Dipietromaria A, Todeschini AL, Caburet S, Bazin C, Anttonen $\mathrm{M}$ and Veitia RA: Transcription factor FOXL2 protects granulosa cells from stress and delays cell cycle: Role of its regulation by the SIRT1 deacetylase. Hum Mol Genet 20: 1673-1686, 2011.

104. Kojima YA, Assylbekova B, Zhao B, Nugent E and Brown RE: Morphoproteomics identifies the EZH2 and SIRT1 pathways as potential blocks to differentiation in yolk sac tumor of the ovary and provides therapeutic options: A case study. Ann Clin Lab Sci 47: 88-91, 2017.

105. De U, Son JY, Sachan R, Park YJ, Kang D, Yoon K, Lee BM, Kim IS, Moon HR and Kim HS: A new synthetic histone deacetylase inhibitor, MHY2256, induces apoptosis and autophagy cell death in endometrial cancer cells via p53 acetylation. Int J Mol Sci 19: 2743, 2018.

106. Van Sinderen M, Griffiths M, Menkhorst E, Niven K and Dimitriadis E: Restoration of microRNA-29c in type I endometrioid cancer reduced endometrial cancer cell growth. Oncol Lett 18: 2684-2693, 2019.

107. Lv Y, Chen S, Wu J, Lin R, Zhou L, Chen G, Chen H and Ke Y: Upregulation of long non-coding RNA OGFRP1 facilitates endometrial cancer by regulating miR-124-3p/SIRT1 axis and by activating PI3K/AKT/GSK-3 $\beta$ pathway. Artif Cells Nanomed Biotechnol 47: 2083-2090, 2019. 
108. Nan P, Niu Y, Wang X and Li Q: MiR-29a function as tumor suppressor in cervical cancer by targeting SIRT1 and predict patient prognosis. Onco Targets Ther 12: 6917-6925, 2019.

109. Edatt L, Maurya AK, Raji G, Kunhiraman H and Kumar SVB: MicroRNA106a regulates matrix metalloprotease 9 in a sirtuin-1 dependent mechanism. J Cell Physiol 233: 238-248, 2018.

110. Zhu J, Shi H, Liu H, Wang X and Li F: Long non-coding RNA TUG1 promotes cervical cancer progression by regulating the miR-138-5p-SIRT1 axis. Oncotarget 8: 65253-65264, 2017.

111. Ou L, Wang D, Zhang H, Yu Q and Hua F: Decreased expression of miR-138-5p by lncRNA H19 in cervical cancer promotes tumor proliferation. Oncol Res 26: 401-410, 2018.

112. Ma R, Wu Y, Zhai Y, Hu B, Ma W, Yang W, Yu Q, Chen Z, Workman JL, Yu X and Li S: Exogenous pyruvate represses histone gene expression and inhibits cancer cell proliferation via the NAMPT-NAD ${ }^{+}$-SIRT1 pathway. Nucleic Acids Res 47: 11132-11150, 2019.

113. Zhang Y, Zhang M, Dong H, Yong S, Li X, Olashaw N, Kruk PA, Cheng JQ, Bai W, Chen J, et al: Deacetylation of cortactin by SIRT1 promotes cell migration. Oncogene 28: 445-460, 2009.

114. Mvunta DH, Miyamoto T, Asaka R, Yamada Y, Ando H, Higuchi S, Ida K, Kashima $\mathrm{H}$ and Shiozawa T: SIRT1 regulates the chemoresistance and invasiveness of ovarian carcinoma cells. Transl Oncol 10: 621-631, 2017.

115. Pinton G, Nilsson S and Moro L: Targeting estrogen receptor beta $(E R \beta)$ for treatment of ovarian cancer: Importance of KDM6B and SIRT1 for ER $\beta$ expression and functionality. Oncogenesis 7: 15, 2018

116. Ding YH, Zhou ZW, Ha CF, Zhang XY, Pan ST, He ZX, Edelman JL, Wang D, Yang YX, Zhang X, et al: Alisertib, an Aurora kinase A inhibitor, induces apoptosis and autophagy but inhibits epithelial to mesenchymal transition in human epithelial ovarian cancer cells. Drug Des Devel Ther 9: 425-464 2015.

117. Sun L, Li H, Chen J, Iwasaki Y, Kubota T, Matsuoka M, Shen A, Chen $\mathrm{Q}$ and $\mathrm{Xu}$ Y: PIASy mediates hypoxia-induced SIRT1 transcriptional repression and epithelial-to-mesenchymal transition in ovarian cancer cells. J Cell Sci 126: 3939-3947, 2013

118. de Jong E, Winkel P, Poelstra K and Prakash J: Anticancer effects of 15d-prostaglandin-J2 in wild-type and doxorubicin-resistant ovarian cancer cells: Novel actions on SIRT1 and HDAC. PLoS One 6: e25192, 2011

119. Yang T, Zhou R, Yu S, Yu S, Cui Z, Hu P, Liu J, Qiao Q and Zhang J: Cytoplasmic SIRT1 inhibits cell migration and invasion by impeding epithelial-mesenchymal transition in ovarian carcinoma. Mol Cell Biochem 459: 157-169, 2019.

120. Zhang X, Chen J, Sun L and Xu Y: SIRT1 deacetylates KLF4 to activate Claudin-5 transcription in ovarian cancer cells. J Cell Biochem 119: 2418-2426, 2018

121. Ray U, Roy SS and Chowdhury SR: Lysophosphatidic acid promotes epithelial to mesenchymal transition in ovarian cancer cells by repressing SIRT1. Cell Physiol Biochem 41: 795-805, 2017.

122. Hou M, Zuo X, Li C, Zhang Y and Teng Y: Mir-29b regulates oxidative stress by targeting SIRT1 in ovarian cancer cells. Cell Physiol Biochem 43: 1767-1776, 2017.

123. Yang A, Wang X, Yu C, Jin Z, Wei L, Cao J, Wang Q, Zhang M, Zhang L, Zhang L and Hao C: MicroRNA-494 is a potential prognostic marker and inhibits cellular proliferation, migration and invasion by targeting SIRT1 in epithelial ovarian cancer. Oncol Lett 14: 3177-3184, 2017.

124. Chen X, Zhang XL, Zhang GH and Gao YF: Artesunate promotes $\mathrm{Th} 1$ differentiation from $\mathrm{CD} 4^{+} \mathrm{T}$ cells to enhance cell apoptosis in ovarian cancer via miR-142. Braz J Med Biol Res 52: e7992, 2019.
125. Tae IH, Park EY, Dey P, Son JY, Lee SY, Jung JH, Saloni S, Kim MH and Kim HS: Novel SIRT1 inhibitor 15-deoxy-delta12,14-prostaglandin $\mathrm{J} 2$ and its derivatives exhibit anticancer activity through apoptotic or autophagic cell death pathways in SKOV3 cells. Int J Oncol 53: 2518-2530, 2018.

126. Al-Wahab Z, Mert I, Tebbe C, Chhina J, Hijaz M, Morris RT, Ali-Fehmi R, Giri S, Munkarah AR and Rattan R: Metformin prevents aggressive ovarian cancer growth driven by high-energy diet: Similarity with calorie restriction. Oncotarget 6 : 10908-10923, 2015.

127. Al-Wahab Z, Tebbe C, Chhina J, Dar SA, Morris RT, Ali-Fehmi R, Giri S, Munkarah AR and Rattan R: Dietary energy balance modulates ovarian cancer progression and metastasis. Oncotarget 5: 6063-6075, 2014

128. Wang Y, Zhang L, Che X, Li W, Liu Z and Jiang J: Roles of SIRT1/FoxO1/SREBP-1 in the development of progestin resistance in endometrial cancer. Arch Gynecol Obstet 298: 961-969, 2018.

129. Xia X and Zhou X: Knockdown of SIRT1 inhibits proliferation and promotes apoptosis of paclitaxel-resistant human cervical cancer cells. Cell Mol Biol (Noisy-le-grand) 64: 36-41, 2018.

130. Raji GR, Sruthi TV, Edatt L, Haritha K, Sharath Shankar S and Sameer Kumar VB: Horizontal transfer of miR-106a/b from cisplatin resistant hepatocarcinoma cells can alter the sensitivity of cervical cancer cells to cisplatin. Cell Signal 38: 146-158, 2017.

131. Chen H, Zhang W, Cheng X, Guo L, Xie S, Ma Y, Guo N and Shi M: $\beta 2-A R$ activation induces chemoresistance by modulating p53 acetylation through upregulating Sirt1 in cervical cancer cells. Cancer Sci 108: 1310-1317, 2017.

132. Teramae M, Fukuda T, Wada T, Kawanishi M, Imai K, Yamauchi M, Yasui T and Sumi T: Sirtuin1 expression predicts the efficacy of neoadjuvant chemotherapy for locally advanced uterine cervical cancer. Mol Clin Oncol 3: 73-78, 2015.

133. Shuang T, Wang M, Zhou Y and Shi C: Over-expression of Sirt1 contributes to chemoresistance and indicates poor prognosis in serous epithelial ovarian cancer (EOC). Med Oncol 32: 260, 2015.

134. Akhter MZ, Sharawat SK, Kumar V, Kochat V, Equbal Z, Ramakrishnan M, Kumar U, Mathur S, Kumar L and Mukhopadhyay A: Aggressive serous epithelial ovarian cancer is potentially propagated by $\mathrm{EpCAM}^{+} \mathrm{CD} 45^{+}$phenotype. Oncogene 37: 2089-2103, 2018.

135. Björklund M, Roos J, Gogvadze V and Shoshan M: Resveratrol induces SIRT1- and energy-stress-independent inhibition of tumor cell regrowth after low-dose platinum treatment. Cancer Chemother Pharmacol 68: 1459-1467, 2011.

136. National Comprehensive Cancer Network. (NCCN) Clinical Practice Guidelines in Oncology. Ovarian Cancer,Version 3.2019. https://www.nccn.org/professionals/physician_gls/f_guidelines. asp. Accessed November 26, 2019.

137. Lord CJ and Ashworth A: BRCAness revisited. Nat Rev Cancer 16: 110-120, 2016.

138. Talens F, Jalving M, Gietema JA and Van Vugt MA: Therapeutic targeting and patient selection for cancers with homologous recombination defects. Expert Opin Drug Discov 12: 565-581, 2017.

139. Chung HT and Joe Y: Antagonistic crosstalk between SIRT1, PARP-1, and -2 in the regulation of chronic inflammation associated with aging and metabolic diseases. Integr Med Res 3: 198-203, 2014

140. El Ramy R, Magroun N, Messadecq N, Gauthier LR, Boussin FD, Kolthur-Seetharam U, Schreiber V, McBurney MW, Sassone-Corsi P and Dantzer F: Functional interplay between Parp-1 and SirT1 in genome integrity and chromatin-based processes. Cell Mol Life Sci 66: 3219-3234, 2009.

This work is licensed under a Creative Commons Attribution-NonCommercial-NoDerivatives 4.0 International (CC BY-NC-ND 4.0) License. 